\title{
New Challenges in the Age of "Industry 4.0": Digital Rhetoric of the Government and News Media
}

\author{
Ayşe Fulya Şen \\ Faculty of Communication, Firat University, Elazig, Turkey \\ Email: fulyasen@firat.edu.tr
}

How to cite this paper: Sen, A. F. (2021). New Challenges in the Age of "Industry 4.0": Digital Rhetoric of the Government and News Media. Advances in Applied Sociology, 11, 659-668.

https://doi.org/10.4236/aasoci.2021.1112055

Received: November 13, 2021

Accepted: December 21, 2021

Published: December 24, 2021

Copyright $\odot 2021$ by author(s) and Scientific Research Publishing Inc. This work is licensed under the Creative Commons Attribution International License (CC BY 4.0).

http://creativecommons.org/licenses/by/4.0/

(c) (i) Open Access

\begin{abstract}
"Industry 4.0" and its own component "artificial intelligence" have been discussed in recent years. Industry 4.0 refers to the fourth industrial revolution. Governments, economists, managers, intellectuals, and consultants celebrate it because it promises economic growth. This process means that everything will change. Therefore, some critical thinkers, like Fuchs (2018), are skeptical of Industry 4.0 due to technological unemployment and its structural crisis potential. In this context, in order to understand how Turkey deals with this issue, it has been discussed how the Ministry of Industry and Technology and the mainstream news media depict Industry 4.0 and artificial intelligence matters. This study tries to explore the dominant discourses on Industry 4.0 topic through the tweets of both the ministry as a public agency and the news media and aims to reveal the ideological approach concerning "Industry 4.0" by analyzing the dominant/mainstream discourses on Twitter. The frequency distribution of the relevant tweets, the tone of the tweets, and the main themes of tweets on "Industry 4.0" and "artificial intelligence" have been analyzed by the content analysis method. Thus, it has been revealed the discursive expressions of the Ministry of Industry and Technology as a governmental agency and the mainstream news media on Twitter and concluded that the dominant rhetoric intensifies on the notion of a technological revolution, transformation, and the positive consequences of $\mathrm{AI}$ in the various fields in human lives. Hence, it has been ignored the critical public debates on this matter.
\end{abstract}

\section{Keywords}

Industry 4.0, Artificial Intelligence, Digital Capitalism, Rhetoric, Social Media 


\section{Introduction}

The world undergoes a profound digital transformation. On the threshold of the next production revolution, it is estimated that ongoing transformations in industry and production activities will be unprecedented level in terms of their scale and impact. Increasing technological developments will bring widespread automation and irreversible shifts in the structure of jobs, raising significant challenges on labor markets and for policymakers responsible for promoting the necessary skills and employment. Artificial intelligence (AI) is defined as the ability of machines and systems to acquire knowledge and carry out cognitive tasks and intelligent behaviors. It empowers new kinds of software and robots to learn and operate independently from human decisions and become self-governing agents (Kergroach, 2017). The concept of industry 4.0 refers to the combination of the Internet of Things, big data, social media, cloud computing, sensors, Artificial Intelligence, robotics, and the application of the combination of these technologies to the production, distribution and use of physical goods (Fuchs, 2018). Fuchs (2018) evaluates this "industry 4.0" process developed in recent years as a new ideology and points out a public debate about "Industry 4.0" through government policy documents and research projects.

Informational capitalism, which has been termed by Castells, refers to the new kind of economic organization imposing its logic on all areas of production and consumption. The network enterprise is de-territorialized, internally de-centralized, and segmented across various chains of production and distribution. The shifts within the capitalist mode of production have led to associated changes in employment and labor. Hence, a new kind of economic and social arrangement such as the decline of manual labor and the rise of the service sector, has emerged. In particular, robots or automated systems will be more apparent in the workplaces (Siapera, 2018).

The connection between market and labor control in digital capitalism is based on the exploitation of human labor. The main targets of new digital applications involve the expansion of digital forms of control over employees and increased use of potentials for automation that result from current developments in robotics. For example, Amazon has shown huge efforts in building a tight and efficient system of digital control focusing not so much on automation but on the extraction of value from human labor. Amazon's fulfillment centers represent a kind of laboratory set-up for developments that are underway in diverse branches of the economy. Digital monopoly capitalism develops new applications of technology in order to raise productivity of labor (Staab \& Nachtwey, 2016: p. 465, p. 467). Schiller (2015) claims that digital capitalism weakens democracy given that governments expand repressive practices, and corporations stake claims to profit out of public goods and institute surveillance of workers and customers. Thus, a new wave of digitized automation threatens to turn an unprecedented number of jobs.

Fuchs (2018) draws attention to the rhetoric of the mainstream debates about 
industry 4.0 technologies. While there is much talk about the economic growth potentials of industry 4.0 technologies, but hardly any debate about the negative impacts of these transformations. According to Fuchs (2018), while it is highlighted its positive impacts on production in Germany, it is ignored aspects of the class struggle, and it is proclaimed a revolution before it has taken place. Hence, Industry 4.0 is evaluated as an attempt to talk a new technological paradigm ideologically into existence. Furthermore, Kergroach (2017) points out the inequalities and social cleavage that may potentially arise from the technological changes. Accordingly, inequalities will not only result from job destruction and employment polarization, but also from weaker social mobility and the persisting digital divide. The Financial Times's economics correspondent, Sarah O'Connor, has visited Amazon's vast distribution center at Rugeley in Staffordshire and shared her observations: “... Inside, hundreds of people in orange vests are pushing trolleys around a space the size of nine football pitches, glancing down at the screens of their handheld satnav computers for directions on where to walk next and what to pick up when they get there. They do not dawdle, the devices in their hands are also measuring their productivity in real time. They might each walk between seven and 15 miles today" (O'Connor, 2013). This citation exemplifies human automation.

In the age of digital capitalism, capitalist companies control the Internet. Most web usage means digital labor that creates commodities and profit that is owned by private companies. The Internet is dominated mainly by the exploitation of digital labour. Digital media are information technologies and are used and applied as tools of cognition, communication and collaboration and therefore have a crucial cultural dimension of usage, work and labor. The world of digital media is shaped by a sophisticated global articulation of various modes of production that together constitute the capitalist mode of creating and using digital media. The digital tools used for writing, reading, communicating, uploading, browsing, collaborating, chatting, befriending, or liking are embedded into a world of exploitation (Fuchs \& Sevignani, 2013; Fuchs \& Sandoval, 2014). The "post-Fordist phase" of capitalism is legitimated by technology discourse. The myths on how digital technology influences in society positively are crucial in building discourses towards sustaining dominant capitalist system. The myths legitimising the status quo are used as a weapon to control political debates, work to depoliticise discourses as a crucial component of hegemonies, thus making it difficult for a counter-hegemonic discourse to arise (Brevini, 2021: p. 146).

In this research, it has been discussed how the Turkish Ministry of Industry and Technology and the mainstream news media depict Industry 4.0 and artificial intelligence matters. This study tries to explore the dominant discourses on Industry 4.0 topic through Twitter accounts of both the ministry as a public agency and the news media and aims to reveal the ideological approach concerning "Industry 4.0 " by analyzing the dominant/mainstream discourses on social media. This research provides an insight into what kind of discourse was generated against the destructive influences of Industry 4.0 and AI and how so- 
cial struggle can be raised over the control and shaping of digital technology. This research analyses the tweets of The Ministry of Industry and Technology, Hürriyet, and Sabah newspapers, provides an insight into what kind of discourse was generated against the destructive influences of Industry 4.0 and AI, and how social struggle can be raised over the control of digital technology. The frequency distribution of the relevant tweets, the tone of the tweets, and the main themes of tweets on "Industry 4.0" and "artificial intelligence" have been analyzed by the content analysis method. To sum up, the analysis of the digital rhetoric about the Fourth Industrial Revolution in the media can help to identify and put forward to the different approaches on the experiences of suffering, security and insecurity, alienation, and appropriation. As Fuchs and Sandoval (2014) note that the analysis of the human dimension of digital capitalism contributes to questioning this mode of human existence in the age of "Industry 4.0".

\section{Literature Review}

The term "Industry 4.0" referred to as the fourth industrial revolution refers to a set of technological advances that are having a high impact on the current industrial landscape. This concept contains the Internet, which is frequently known as the "Internet of Things", the integration of IT systems and the interconnection between the whole supply chain transforming today's factories into Industry 4.0 factories. The Internet of Things (IoT) is an emerging term that combines different technologies and approaches, based on the connection between physical things and the Internet. The Internet of Services (IoS) concept has emerged recently and is evaluated as a new opportunity to the service industry and provides a business and technical basis for business networks creation between service providers and customers (Pereira \& Romero, 2017). The concepts of smart factory, smart manufacturing, intelligent factory, factory of the future, new systems in the development of products and services, self-organization, smart product, cyber-physical systems, digital sustainability compose the components of Industry 4.0 (Roblek et al., 2016). In general, the influence of Industry 4.0 and Internet-connected technologies are depicted positively. Asadollahi-Yazdi et al. (2020: p. 248, p. 265) mention the elements of Industry 4.0 providing numerous benefits for the industrial world such as productivity, agility, innovation, customer experience, cost, and revenue and also draw attention to some of the Industry 4.0's risks. The digital transformation will lead to a change of the certain professions in the near future, so some professions are at risk of disappearing. Therefore, basic changes and new skills are also necessary to adapt to these new professions. For this purpose, industrial sectors need to analyze their level of digital maturity in order to remain in this competitive world.

In the new era of technological determinism, it is assumed that Artificial Intelligence is now inevitable and ubiquitous. Rehak (2021: p. 99) argues that technology is used and politically decided upon perceived functionality, not 
upon the actually implemented functionality. Verdegem (2021) deals with the foundations of why critical perspectives are necessary to overcome utopian and dystopian perspectives on AI and develops the argument why we need to ask critical questions and come up with a vision towards AI to benefit society at large. Verdegem (2021: pp. 9-10) proposes that AI policies and ethics help us to explore questions of what type of AI we want/need and how we deal with its impact. Accordingly, while AI policies reflect the priorities of the stakeholders involved, it should be considered what type of AI is preferred along with potential risks. At this point, the critical analysis of AI brings provides to understand two points: 1) the problem of AI ideology and 2) the limitations of ethics. The technological paradigm is thus a major component of hegemonic ideology helping to maintain the essential structures of the current capitalist system and making coherent and viable alternatives increasingly difficult to envision. AI ideology thus propagates one specific vision of what AI is and what it should doincluding serving the interests of the ruling class -and discourages alternative visions from materializing.

In order to be aware of the limitation and missing of Industry 4.0 and AI, it is crucial to investigate how the policies and discourses are formulated and justified. In this study, a critical analysis has been carried out over the digital rhetoric of the main actors producing and spreading the messages of Industry 4.0 and AI digital transformation to society. Thus, it has been revealed the discursive expressions of the Ministry of Industry and Technology as a governmental agency and the mainstream news media on Twitter. Hess (2017: p. 6) defines "digital rhetoric" as the study of meaning making, persuasion, or identification as expressed through language, bodies, machines, and texts that are created, circulated or experienced through or regarding digital technologies. Simply, the "digital rhetoric" term refers to the use of language in digital texts. Digital rhetoric contains the use of rhetorical strategies in the production and analysis of a digital text (Eyman, 2015). Since digital rhetoric discloses and reflects the political and economic dynamics of Industry 4.0 and AI, it has been used as a methodological tool to find manipulated aspects of this discourse.

\section{Methodology}

In this context, in order to reveal the digital rhetoric related to the Next Production Revolution and to identify the issues related to "industry 4.0 ", it has been carried out qualitative and quantitative analyses. Firstly, it has been analyzed the digital rhetoric of the government and news media about the fourth industrial revolution. In order to illustrate the discourses related to the digital structural change, it has been analyzed the forms of writing on social networking platforms of the structures mentioned above. While mapping dominant discourses, Twitter is an excellent resource in collecting data for sentiment analyses.

The objective of sentiment analysis is to examine by type the tweets of the Ministry of Industry and Technology as a public agency and Hürriyet and Sabah 
dailies representing mainstream media. The categorization has been distinguished between three kinds of tweets according to their polarity score: the positive tweets, the neutral tweets, and the negative tweets. In addition to this analysis, it has been examined discourses on social media of the Ministry of Industry and Technology and the news organizations over the keywords and the sentiment analysis outputs have been compared.

In order to understand the mainstream thoughts and tendencies towards Industry 4.0 and AI under the digital capitalism process, it has been conducted qualitative content analysis over the tweets of The Ministry of Industry and Technology as a government agency, Hürriyet and Sabah newspapers. Hence, this research aim to identify similarities and differences between the public sector and news media on digital capitalism forms under "Industry 4.0" and whether these agencies discuss the different aspects of "Industry 4.0" critically. Accordingly, 87 tweets of the sampling units have been investigated as of the date of 20th June 2021 through the keywords, "Industry 4.0", "Artificial Intelligence" (AI). The data has been collected from the identified Twitter accounts. Then, these tweets containing these concepts and certain keywords reflecting the policy approaches have been analyzed in terms of their discourses and ideologies.

\section{Findings and Analysis}

This section contains discourses about AI and Industry 4.0 on Twitter by qualitative content analysis. In order to reveal the technological deterministic discourses, the tweets of the Ministry of Industry and Technology that represents the voice of the Government and the tweets of mainstream news media selected have been analyzed.

When it was searched via "industry 4.0" and "artificial intelligence" words within the sampling framework, it is reached only 87 tweets. The frequency distribution of the tweets as of the date June 2021 points out a low coverage (Table 1).

The Ministry of Industry and Technology has tweeted about "Industry 4.0" supportively. All tweets contain matters on technological planning strategy and investments. Especially, the private sector is marked as the main actor in this transformation. There is no information and planning about its impacts on the workforce. It can be said that there is no awareness of "Industry 4.0 " matter in the two main actors of Turkish news media, Hürriyet and Sabah. While Hürriyet has no tweet on this topic, Sabah has only one tweet. Under science journalism notion, the news organizations should convey reporting about science to the public, but "Industry 4.0 " concept has not been dealt with on Twitter (Table 2).

As to the frame of The Ministry of Industry and Technology on "artificial intelligence", all tweets are related to the conferences and summits on this matter (Table 3). Except for this, it has been mentioned a decision on that AI and robotic technologies would be developed in the industry sector in the only one tweet. Hürriyet has shared content on artificial intelligence mostly neutral and 
supportive and emphasized its power on humanity. These tweets have also covered the success stories. However, Hürriyet has shared the news on the disappearance of some occupations in near future because of artificial intelligence. These kinds of content have been coded as critical due to bringing about new questions and mentioning the negative impacts of artificial intelligence on human lives. Sabah has tweet coverage on "artificial intelligence" which is supportive and also neutral mostly. These tweets focus on the successful consequences of AI in terms of medical treatments. On the other hand, only three tweets have contained some concerns about AI how it threatens humanity, however, these do not point out the destructive consequences of the probable loss of jobs in the near future and the solutions of the capitalist system.

In order to reveal how the government and news media define the technological transformation calling "industry 4.0" and AI and produce the dominant discourses on these changes, tweets have been classified via certain key themes. Table 4 shows that the dominant rhetoric intensifies on the notion of technological revolution-transformation and the consequences of $\mathrm{AI}$ in the various fields

Table 1. The frequency distribution of the relevant tweets (20th June 2021).

\begin{tabular}{cccc}
\hline $\begin{array}{c}\text { The Government and } \\
\text { News Media Key Words }\end{array}$ & $\begin{array}{c}\text { The Ministry of Industry and } \\
\text { Technology @TCSanayi }\end{array}$ & $\begin{array}{c}\text { Hürriyet } \\
\text { @Hurriyet }\end{array}$ & $\begin{array}{c}\text { Sabah } \\
\text { @Sabah }\end{array}$ \\
\hline Industry 4.0 & 15 & - & 1 \\
Artificial Intelligence & 15 & 36 & 20 \\
Total & 30 & 36 & 21 \\
\hline
\end{tabular}

Table 2. The tone of the tweets (Industry 4.0) (20th June 2021).

\begin{tabular}{cccc}
\hline & Supportive & Neutral & Critical \\
\hline $\begin{array}{c}\text { The Ministry of Industry and Technology } \\
\text { @TCSanayi }\end{array}$ & 15 & - & - \\
Hürriyet & & - & - \\
@Hurriyet & - & - & - \\
Sabah & & & - \\
@Sabah & 1 & - & - \\
Total & 16 & - & \\
\hline
\end{tabular}

Table 3. The tone of the tweets (Artificial Intelligence) (20th June 2021).

\begin{tabular}{|c|c|c|c|}
\hline & Supportive & Neutral & Critical \\
\hline $\begin{array}{l}\text { The Ministry of Industry and Technology } \\
\text { @TCSanayi }\end{array}$ & 15 & - & - \\
\hline $\begin{array}{l}\text { Hürriyet } \\
\text { @Hurriyet }\end{array}$ & 13 & 15 & 8 \\
\hline $\begin{array}{l}\text { Sabah } \\
@ \text { Sabah }\end{array}$ & 10 & 7 & 3 \\
\hline Total & 38 & 22 & 11 \\
\hline
\end{tabular}


Table 4. The main themes of tweets coverage on "Industry 4.0 " and "artificial intelligence" (20th June 2021).

\begin{tabular}{cc}
\hline Main Theme & Number of tweets \\
\hline Efficiency-production & 2 \\
Profit-investment & 2 \\
R\&D-Innovation & 3 \\
Technological revolution-transformation-strategy & 34 \\
Uses of artificial intelligence & 31 \\
Humans' success stories & 4 \\
Loss of job-threat to humanity & 11 \\
Digital labor & - \\
Digital inequality & - \\
Total & $\mathbf{8 7}$ \\
\hline
\end{tabular}

in human lives. The sub-themes such as profit, investment, R\&D, and innovation also complement the dominant discourse. In addition, it can be said that the critical perspective is so weak in terms of understanding all aspects of these developments. The technological transformations of newsrooms, the rising of challenges for the journalists, and the unemployment wave in the future have been underrepresented in the tweets. These findings reveal that these actors do not discuss how AI protects labor, provides a benefit for human development and enhances social welfare rights by minimizing risks (Walton \& Nayak, 2021). Development of digital technology is naturalized by market-based ideology. The myths employed in official EU plans become crucial components of AI discourse, justifying policy-making within the European Union. Furthermore, these myths construct a discourse reinforcing the current neoliberal ideology of the current stage of capitalism. These myths are that artificial intelligence is a solution for humanity and capitalism's biggest challenges, creates urgency and prepares society, and surpasses human intelligence (Brevini, 2021: pp. 147-154). The findings show that the discourses on AI are conformed to these dominant myths and $\mathrm{AI}$ is represented as the solution to the major problems.

\section{Conclusion}

Industry 4.0 concept has three aspects, digitization of production, automation, and linking manufacturing sites in a comprehensive supply chain. Industry 4.0 is not limited to robotics and the automation of production because it is digitization of business processes as a whole. It also involves the adoption of a contract over the procurement of materials, and how the product "gets" through production and is finally delivered to the customer. In this area, it is expected certain automaticity of the workers (Roblek et al., 2016). AI development is dominated by capital, led by some of the world's most powerful oligopolistic corporations, enabled by and assisting nation-states seeking instruments of economic compe- 
tition in the world market and weapons for their military and security forces (Dyer-Witheford et al., 2019). It is important to understand the political economy background of the Industry 4.0 ideology. As Fuchs (2018: p. 284) noted, capital and labor represent opposed interests to the process of automation. While capital wants to reduce labor costs and maximize profits, labor aims to maximize the universal and collective control of wealth and production, to minimize toil and realize a good life for all. Digitalization process faces in capitalism a struggle between profit interests and human interests.

It is claimed that AI and big data are not ideologically neutral scientific knowledge that drives economic development and social change. AI is a tool of capitalism that transforms societies within an environment of a technological singularity that helps in the expansion of the capitalist model of economic development. Such a development process leads to the precarity of labor. AI and its technological singularity cause a digital divide based on availability and accessibility to technological knowledge and its infrastructure. Therefore, it has the potential to further expand existing societal rifts and class conflicts (Walton \& Nayak, 2021). What expected from the public authorities and the news media is that they protect the public interest and pioneer public debates on the policies of AI. When we look at their tweet flows, a rational public debate is not seen in the digital public sphere. It needs questioning the capital concentration and monopolization in the technological transformation process, its probable impacts and how to arrange labor regime in which humans work with robots, and whether the governments are ready for this new system. The development of AI and the potential of automation technology can give rise to unintended consequences, like job losses. Therefore, AI policies should be planned with social security approaches and constructed a counter-public sphere where multiple actors discuss various narratives. Future studies might investigate the discourse of both political actors and news media in the wider ranges so that it can be increased awareness on digital transformations in the Industry 4.0 process and its relationship with capitalism.

\section{Conflicts of Interest}

The author declares no conflicts of interest regarding the publication of this paper.

\section{References}

Asadollahi-Yazdi, E., Couzon, P., Nguyen, N. Q., Ouazene, Y., \& Yalaoui, F. (2020). Industry 4.0: Revolution or Evolution? American Journal of Operations Research, 10, 241-268. https://doi.org/10.4236/ajor.2020.106014

Brevini, B. (2021). Creating the Technological Saviour: Discourses on AI in Europe and the Legitimation of Super Capitalism. In P. Verdegem (Ed.), AI for Everyone? Critical Perspectives (pp. 145-159). University of Westminster Press.

Dyer-Witheford, N., Kjøsen, A., \& Steinhoff, J. (2019). Conclusion: Communist AI. In Inhuman Power: Artificial Intelligence and the Future of Capitalism (pp. 145-162). 
Pluto Press. https://doi.org/10.2307/j.ctvj4sxc6.9

Eyman, D. (2015). Digital Rhetoric: Theory, Method, Practice. University of Michigan Press. http://www.digitalculture.org/books/digital-rhetoric/ https://doi.org/10.2307/j.ctv65swm2

Fuchs, C. (2018). Industry 4.0: The Digital German Ideology. TripleC, 16, 280-289. https://www.triple-c.at/index.php/tripleC/article/view/1010

Fuchs, C., \& Sandoval, M. (2014). Digital Workers of the World Unite! A Framework for Critically Theorising and Analysing Digital Labour. TripleC, 12, 486-563. https://www.triple-c.at/index.php/tripleC/article/view/549

Fuchs, C., \& Sevignani, S. (2013). What Is Digital Labour? What Is Digital Work? What's Their Difference? and Why Do These Questions Matter for Understanding Social Media? TripleC, 11, 237-293. https://www.triple-c.at/index.php/tripleC/article/view/461

Hess, A. (2017). Introduction: Theorizing Digital Rhetoric. In A. Hess, \& A. Davisson (Eds.), Theorizing Digital Rhetoric (pp. 1-15). Routledge.

https://doi.org/10.4324/9781315203645-1

Kergroach, S. (2017). Industry 4.0: New Challenges and Opportunities for the Labour Market. Foresight and STI Governance, 11, 6-8. https://doi.org/10.17323/2500-2597.2017.4.6.8

O’Connor, S. (2013). Amazon Unpacked. Financial Times. https://www.ft.com/content/ed6a985c-70bd-11e2-85d0-00144feab49a\#slide0

Pereira, A. C., \& Romero, F. (2017). A Review of the Meanings and the Implications of the Industry 4.0 Concept. Procedia Manufacturing, 13, 1206-1214. https://doi.org/10.1016/j.promfg.2017.09.032

Rehak, R. (2021). The Language Labyrinth: Constructive Critique on the Terminology Used in the AI Discourse. In P. Verdegem, (Ed.), AI for Everyone? Critical Perspectives (pp. 87-102). University of Westminster Press.

Roblek, V., Meško, M., \& Krapež, A. (2016). A Complex View of Industry 4.0. SAGE Open. https://doi.org/10.1177/2158244016653987

Schiller, D. (2015). Digital Capitalism: Stagnation and Contention? openDemocracy. https://www.opendemocracy.net/digitaliberties/dan-schiller/digital-capitalism-stagnati on-and-contention

Siapera, E. (2018). Understanding New Media. Sage.

Staab, P., \& Nachtwey, O. (2016). Market and Labour Control in Digital Capitalism. TripleC, 14, 457-474. https://www.triple-c.at/index.php/tripleC/article/view/755

Verdegem, P. (2021). Introduction: Why We Need Critical Perspectives on AI. In P. Verdegem, (Ed.), AI for Everyone? Critical Perspectives (pp. 1-18). University of Westminster Press.

Walton, N., \& Nayak, B. S. (2021). Rethinking of Marxist Perspectives on Big Data, Artificial Intelligence (AI) and Capitalist Economic Development. Technological Forecasting and Social Change, 166, Article ID: 120576.

https://doi.org/10.1016/j.techfore.2021.120576 